\title{
1D PtCo nanowires as catalysts for PEMFCs with low Pt loading
}

\author{
Jin Huang ${ }^{1 \dagger}$, Bosi Peng ${ }^{1,2 \dagger}$, Thomas Stracensky ${ }^{3}$, Zeyan Liu ${ }^{1}$, Ao Zhang ${ }^{1}$, Mingjie $\mathrm{Xu}^{4,5}$, Yang Liu ${ }^{1}$, \\ Zipeng Zhao ${ }^{1}$, Xiangfeng Duan ${ }^{2,6}$, Qingying Jia ${ }^{3}$ and Yu Huang ${ }^{1,6^{*}}$
}

\begin{abstract}
The high cost of platinum (Pt)-group metal (PGM)-based catalysts used in proton-exchange membrane fuel cells (PEMFCs) poses a critical roadblock to their widespread adoption. Although using low PGM loading PEMFCs can largely address this challenge, high current density performance will be severely compromised consequently. To overcome this dilemma, we report the development of ultrathin platinum-cobalt nanowires (PtCoNWs) as the cathode catalysts for ultralow $\mathrm{Pt}$ loading and high-performance membrane electrode assembly (MEA). The PtCoNWs delivered a record-high mass activity (MA) of $1.06 \pm 0.14 \mathrm{~A} \mathrm{mg}_{\mathrm{Pt}_{\mathrm{t}}}{ }^{-1}$ of Pt-alloy catalysts towards oxygen reduction reaction (ORR) in MEA, yielding an impressive total $\mathrm{Pt}$ utilization of $5.14 \mathrm{~W}_{\text {rated }} \mathrm{mg}_{\mathrm{Pt}^{-}}{ }^{-1}$. The PtCoNWs retained a respectable endof-life MA of $0.45 \mathrm{~A} \mathrm{mg}_{\mathrm{pt}}{ }^{-1}$ after the 30,000 cycles square-wave accelerated stability test, which is still above the Department of Energy 2020 beginning-of-life target for catalysts. In-situ Xray absorption spectroscopy studies suggest that the high degree of alloying in the PtCoNWs stabilizes the ultrathin structure and may contribute to the high ORR activity and power density performance in PEMFC.
\end{abstract}

Keywords: ultralow loading, PtCo nanowires, high mass activity, high Pt utilization, fuel cell

\section{INTRODUCTION}

Proton-exchange membrane fuel cells (PEMFCs) represent an attractive and sustainable power generation technology in automotive applications [1-3]. Although platinum (Pt)-group metal (PGM) materials represent the most efficient catalysts facilitating the sluggish oxygen reduction reaction (ORR) in PEMFCs [2,4], the high cost of Pt and related components has severely impeded the broad dissemination of PEMFCs $[5,6]$. In principle, it is highly desirable to minimize the usage of $\mathrm{Pt}$ while achieving high performance. The Department of Energy (DOE) has set a beginning-of-life (BOL) mass activity (MA) target of $0.44 \mathrm{~A} \mathrm{mg}_{\mathrm{PGM}}{ }^{-1}$ and a total loading target of $0.125 \mathrm{mg}_{\mathrm{PGM}} \mathrm{cm}^{-2}$ by 2020 , and planned to further lower the loading to $0.1 \mathrm{mg}_{\mathrm{PGM}} \mathrm{cm}^{-2}[6,7]$.

To this end, developing practical high-performance ORR catalysts for a membrane electrode assembly (MEA) with high MA and high power density is essential for minimizing Pt usage $[3,8,9]$. In general, Pt-alloy catalysts show much improved catalytic activity than pure $\mathrm{Pt}$ in rotating disk electrode (RDE) measurements owing to their adjusted $\mathrm{Pt}-\mathrm{O}$ binding strength [10-13]. However, the higher activity does not necessarily translate directly to MEA. In addition, reducing the PGM loading while keeping the power density performance and stability adds more challenges due to the more severe mass transport issues and harsher testing conditions in MEA [3,6,14]. Large losses of power density were widely observed for cells with low Pt loadings $\left(<0.1 \mathrm{mg} \mathrm{cm}^{-2}\right)$ due to the decreasing $\mathrm{Pt}$ roughness factor (r.f., units of $\mathrm{cm}^{2}{ }_{\mathrm{Pt}} \mathrm{cm}^{-2} \mathrm{MEA}$ ) and the consequently increasing $\mathrm{O}_{2}$ transport resistance $[3,6,14]$. In essence, to decrease loading while maintaining the same catalyst layer thickness, the interparticle distance became larger, leading to a faster Pt dissolution rate and worse structural stability [14]. This represents an intrinsic dilemma for current low PGM loading MEAs: i.e., the decrease in the usage of Pt usually comes with a substantial sacrifice in power density and stability that leads to low Pt utilization. Therefore, it is of primary importance to design catalysts to overcome the above-said dilemma.

One-dimensional (1D) nanostructures can simultaneously achieve high electrochemical active surface area (ECSA) and $\mathrm{MA}$, offering considerable potential for lowering the Pt loading in PEMFCs $[15,16]$. In addition, 1D nanostructures showed better structural stability than nanoparticles (NPs), which can effectively mitigate aggregation and dissolution [17] and potentially help retain high power density at low PGM loading in MEA. Previously, the jagged-Pt nanowires (NWs) developed by $\mathrm{Li}$ et al. [13] showed a record-high $\mathrm{MA}$ of $13.6 \mathrm{~A} \mathrm{mg}_{\mathrm{Pt}}{ }^{-1}$ towards ORR on the RDE. During the electrochemical dealloying process, NWs could maintain the 1D structure, proving its high structural stability. Bu et al. [18] and Jiang et al. [19] also prepared a series of Pt-alloy NWs, showing respectable activity and stability. Despite promising performance reported for $1 \mathrm{D}$ catalysts in half-cell RDE measurements, the outstanding performance of this new generation of catalysts has not yet been incorporated and investigated in an MEA $[2,3,20,21]$. Furthermore, low PGM loading MEA (e.g., $\leq 0.1 \mathrm{mg}_{\mathrm{PGM}} \mathrm{cm}^{-2}$ planned by 2025) [6] has been rarely reported. Therefore, it is highly

\footnotetext{
${ }^{1}$ Department of Materials Science and Engineering, University of California, Los Angeles, CA 90095, USA

${ }^{2}$ Department of Chemistry and Biochemistry, University of California, Los Angeles, CA 90095, USA

${ }^{3}$ Department of Chemistry and Chemical Biology, Northeastern University, Boston, MA 02115, USA

${ }^{4}$ Irvine Materials Research Institute, University of California, Irvine, CA 92697, USA

${ }^{5}$ Department of Materials Science, University of California, Irvine, CA 92697, USA

${ }^{6}$ California NanoSystems Institute, University of California, Los Angeles, CA 90095, USA

$\dagger$ These authors contributed equally to this work.

* Corresponding author (email: yhuang@seas.ucla.edu)
} 
desirable to incorporate Pt-based NWs into MEAs to fully demonstrate and capture their merit in practical PEMFCs with low Pt loading, owing to their demonstrated high MA and ECSA.

Herein, we demonstrated an ultralow Pt loading (total loading of $0.072 \mathrm{mg}_{\mathrm{Pt}} \mathrm{cm}^{-2}$, cathode loading of $0.047 \mathrm{mg}_{\mathrm{Pt}} \mathrm{cm}^{-2}$ ) and high-performance MEA using ultrathin platinum-cobalt NWs (PtCoNWs) as cathode catalysts. The PtCoNWs showed a high ECSA of $73.2 \mathrm{~m}^{2} \mathrm{~g}_{\mathrm{Pt}}{ }^{-1}$ and achieved an unprecedented MA of $1.06 \pm 0.14 \mathrm{~A} \mathrm{mg}_{\mathrm{Pt}}{ }^{-1}\left(0.9 \mathrm{~V}_{\mathrm{iR}-\text { free }}\right)$ at the BOL stage in MEA. This MA is 3.3 times that of the commercial $\mathrm{Pt} / \mathrm{C}\left(0.32 \mathrm{~A} \mathrm{mg}_{\mathrm{Pt}}{ }^{-1}\right)$ and far surpasses the DOE 2020 target $\left(0.44 \mathrm{~A} \mathrm{mg}_{\mathrm{PGM}^{-1}}{ }^{-1}\right)$. The PtCoNWs reached a peak power density of $1016 \mathrm{~mW} \mathrm{~cm}^{-2}$, outperforming the PtNWs $\left(830 \mathrm{~mW} \mathrm{~cm}^{-2}\right)$ and $\mathrm{Pt} / \mathrm{C}$ $\left(773 \mathrm{~mW} \mathrm{~cm}^{-2}\right.$ ) with comparable Pt loading. After the accelerated stability test (AST), the PtCoNWs showed a respectable end-of-life (EOL) MA of $0.45 \mathrm{~A} \mathrm{mg}_{\mathrm{Pt}}{ }^{-1}$, remaining above the DOE 2020 BOL target.

\section{EXPERIMENTAL SECTION}

\section{Materials}

All chemicals were purchased from Sigma-Aldrich unless otherwise specified. Commercial $\mathrm{Pt} / \mathrm{C}$ catalysts (10 and $40 \mathrm{wt} \%$ Pt) were purchased from Alfa Aesar. Isopropanol ( $\geq 99.5 \%)$ was purchased from Fisher Scientific. All reagents were used as received without further purification. For MEA test, Ketjen-300J carbon was obtained from Lion Specialty Chemicals Co., Ltd. The deionized water $\left(18 \mathrm{M} \Omega \mathrm{cm}^{-1}\right)$ was obtained from an ultrapure purification system (Milli-Q advantage A10). The Nafion HP membrane was purchased from Fuel Cell Store.

\section{Synthesis of PtCoNWs catalysts}

In a typical synthesis of PtCoNWs, $200 \mathrm{mg}$ of platinum(II) acetylacetonate $\left(\mathrm{Pt}(\mathrm{acac})_{2}\right)$ and $100 \mathrm{mg}$ of $\mathrm{Co}(\mathrm{acac})_{2}$ were mixed with $675 \mathrm{mg}$ of glucose, $16 \mathrm{mg}$ of $\mathrm{W}(\mathrm{CO})_{6}$ and $150 \mathrm{mg}$ of polyvinyl pyrrolidone (PVP)-10,000 in a $250-\mathrm{mL}$ glass vial, with $50 \mathrm{~mL}$ of oleylamine and octadecene (3:2 volume ratio) as cosolvent. The mixture was heated to $180^{\circ} \mathrm{C}$ and maintained at this temperature for $6 \mathrm{~h}$ to form the as-prepared PtCo alloy NWs. The resulting NWs were collected via centrifuge at $3000 \mathrm{r} \mathrm{min}^{-1}$ for $10 \mathrm{~min}$. After loading the NWs on carbon (Kejten black), the catalysts were then annealed under $450^{\circ} \mathrm{C}$ in argon/hydrogen (97:3) atmosphere for $6 \mathrm{~h}$ to remove the surfactant. After annealing, the resulting product was dealloyed in $0.5 \mathrm{~mol} \mathrm{~L}^{-1}$ sulfuric acid at $80^{\circ} \mathrm{C}$ for $4 \mathrm{~h}$, washed till the $\mathrm{pH}$ turned neutral, and then annealed in $\mathrm{Ar} / \mathrm{H}_{2}\left(3 \% \mathrm{H}_{2}\right)$ atmosphere at $200^{\circ} \mathrm{C}$ for $2 \mathrm{~h}$ to obtain the final ultrafine PtCoNWs.

\section{Synthesis of PtNWs catalysts}

For comparison, PtNWs were also prepared via a similar synthesis and processing method. Briefly, $200 \mathrm{mg}$ of $\mathrm{Pt}(\mathrm{acac})_{2}$ and $100 \mathrm{mg}$ of $\mathrm{Co}(\mathrm{acac})_{2}$ were mixed with $675 \mathrm{mg}$ of glucose, $16 \mathrm{mg}$ of $\mathrm{W}(\mathrm{CO})_{6}$ and $150 \mathrm{mg}$ of PVP-10,000 in a $250-\mathrm{mL}$ glass vial, with $50 \mathrm{~mL}$ of oleylamine and octadecene (3:2 volume ratio) as co-solvent. The mixture was heated to $120^{\circ} \mathrm{C}$ for $6 \mathrm{~h}$ to form Pt NWs. The resulting NWs were collected via centrifuge at $3000 \mathrm{rmin}^{-1}$ for $10 \mathrm{~min}$. After loading the NWs on carbon (Kejten black), the catalysts were then annealed under $400^{\circ} \mathrm{C}$ in argon/hydrogen (97:3) atmosphere for $6 \mathrm{~h}$. After annealing, the resulting product was dealloyed in $0.5 \mathrm{~mol} \mathrm{~L}^{-1}$ sulfuric acid at $80^{\circ} \mathrm{C}$ for $4 \mathrm{~h}$, washed till the $\mathrm{pH}$ turned neutral, and then annealed in $\mathrm{Ar} / \mathrm{H}_{2}\left(3 \% \mathrm{H}_{2}\right)$ atmosphere at $200^{\circ} \mathrm{C}$ for $2 \mathrm{~h}$ to obtain the final ultrafine PtNWs.

\section{Structure and composition characterization}

Low-magnification transmission electron microscopy (TEM) images were taken on an FEI T12 transmission electron microscope operated at $120 \mathrm{kV}$. High-resolution TEM images (HRTEM), energy-dispersive X-ray spectroscopy (EDX) linescan file, and the high-angle annular dark-field scanning transmission electron microscope (HAADF-STEM) images were taken on a JEM-ARM300F Grand ARM transmission electron microscope operated at $300 \mathrm{kV}$. TEM samples were prepared by dropping ethanol dispersion of catalysts onto carbon-coated aluminum TEM grids. The elementary concentration of catalysts was determined by the inductively coupled plasma atomic emission spectroscopy (ICP-AES). The Pt loading in the catalysts was determined by the catalyst before electrochemical ink preparation. The MEA loading was determined by ICP before and after the MA and power density measurement. In specific, two pieces of sprayed catalysts $\left(2 \mathrm{~cm}^{2}\right)$ were cut and soaked in the aqua regia for one day and were used to prepare ICP solution for metal content measurement. The loading after the MEA measurements was also checked for the accuracy of our results.

\section{Electrochemical measurement}

A three-electrode cell system was used to conduct all electrochemical tests. The working electrode was a glassy carbon RDE with a $0.196 \mathrm{~cm}^{2}$ glassy carbon geometry area from Pine Instruments. The Pt wire and $\mathrm{Ag} / \mathrm{AgCl}\left(1 \mathrm{~mol} \mathrm{~L}^{-1} \mathrm{Cl}^{-}\right)$were used as the counter and reference electrodes, respectively. The loading of the catalysts was controlled to be $7.5 \mu \mathrm{g}_{\mathrm{Pt}} \mathrm{cm}^{-2}$. Cyclic voltammetry $(\mathrm{CV})$ activations were performed in $\mathrm{N}_{2}$-saturated $0.1 \mathrm{~mol} \mathrm{~L}^{-1} \mathrm{HClO}_{4}$ electrolyte with a potential scan rate of $100 \mathrm{mV} \mathrm{s}^{-1}$. ECSA determined by underpotential-deposited hydrogen $\left(\mathrm{H}_{\text {upd }}\right)$ was calculated by integrating the hydrogen adsorption charge on the $\mathrm{CV}$ curve by taking a value of $210 \mu \mathrm{Cm}^{-2}$ for the adsorption of a hydrogen monolayer. Double-layer correction was also applied. ORR was tested in an $\mathrm{O}_{2}$-saturated $0.1 \mathrm{~mol} \mathrm{~L}^{-1} \mathrm{HClO}_{4}$ electrolyte with a potential scan rate of $20 \mathrm{mV} \mathrm{s}^{-1}$. The measurement temperature was set at $25^{\circ} \mathrm{C}$ using a 5-neck flask in water bath. The current density of the ORR polarization curve was iR-corrected. The AST was done at room temperature in $\mathrm{O}_{2}$-saturated $0.1 \mathrm{~mol} \mathrm{~L}^{-1} \mathrm{HClO}_{4}$ solutions by applying CV sweep between 0.6 and $1.0 \mathrm{~V}$ versus reversible hydrogen electrode (RHE) at a sweep rate of $100 \mathrm{mV} \mathrm{s}^{-1}$ for 10,000 cycles.

\section{MEA preparation and single fuel cell test}

The single fuel cell performance of the catalysts as the cathode was tested at an 850e Fuel Cell Test System (Scribner, USA). The MEAs with an active area of $5.0 \mathrm{~cm}^{2}$ were fabricated using the catalyst-spray membrane method. Catalysts were incorporated into MEAs by direct ultrasonic spraying of a water/2-propanolbased ink onto a Nafion HP membrane with desired loading. The anode loading was set to be $0.025 \mathrm{mg}_{\mathrm{Pt}} \mathrm{cm}^{-2}$. The MA was measured via measuring the current at $0.9 \mathrm{~V}$ ( $i R$-free) in $150 \mathrm{kPa}$ absolute pressure (abs) $\mathrm{H}_{2} / \mathrm{O}_{2}\left(80^{\circ} \mathrm{C}, 100 \%\right.$ relative humidity (RH), 835/2000 $\mathrm{cm}^{3} \mathrm{~min}^{-1}$ ) with correction for measured $\mathrm{H}_{2}$ crossover. The $\mathrm{H}_{2}$-Air tests were measured under $150 \mathrm{kPa}_{\mathrm{abs}} \mathrm{H}_{2} /$ Air $\left(80^{\circ} \mathrm{C}, 100 \% \mathrm{RH}, 835 / 2000 \mathrm{~cm}^{3} \mathrm{~min}^{-1}\right)$. The AST was con- 
ducted using the square wave method from 0.6 to $0.95 \mathrm{~V}$ with $3 \mathrm{~s}$ hold time and less than $0.5 \mathrm{~s}$ rise time $\left(150 \mathrm{kPa}_{\mathrm{abs}}, 80^{\circ} \mathrm{C}, 100 \%\right.$ $\left.\mathrm{RH}, \mathrm{H}_{2} / \mathrm{N}_{2}=100 / 100 \mathrm{~cm}^{3} \mathrm{~min}^{-1}\right)$. Rated power voltage $=(77.6 /$ $\left.\left(22.1+T\left({ }^{\circ} \mathrm{C}\right)\right)\right) \mathrm{V}$, based on the target of $\mathrm{Q} / \Delta T i=1.45 \mathrm{~kW}^{\circ} \mathrm{C}^{-1}$ (rated voltage $=0.76 \mathrm{~V}$ for $80^{\circ} \mathrm{C}$ ). The Pt utilization was calculated by normalizing the rated power by total Pt loading.

\section{XAS data collection and analysis}

The electrode inks for the X-ray absorption spectroscopy (XAS) electrodes were composed of ethanol, $5 \mathrm{wt} \%$ Nafion solution (Aldrich), and the catalyst powder $\left(4 \mathrm{mg} \mathrm{mL}^{-1}\right)$. The ink was drop-cast onto a piece of carbon paper with a loading of about $8 \mathrm{mg} \mathrm{cm}^{-2}$. The XAS experiments were conducted at room temperature in a previously described in situ spectro-electrochemical half-cell in which an $\mathrm{O}_{2}$-purged $0.1 \mathrm{~mol} \mathrm{~L}^{-1} \mathrm{HClO}_{4}$ aqueous solution was continuously circulated [22]. Before being transferred into the cell, the electrodes were conditioned in $0.1 \mathrm{~mol} \mathrm{~L}^{-1} \mathrm{HClO}_{4}$ under vacuum for $40 \mathrm{~min}$ to remove surface oxides and contaminants. Potentiostatic control was maintained with an Autolab PGSTAT30 potentiostat (Metrohm USA, formerly Brinkman Instruments). Data were collected on the same

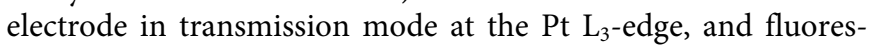
cence mode at the Co K-edge, with a $\mathrm{Pt} / \mathrm{Co}$ reference foil positioned between I 2 and I 3 as a reference. The voltage cycling limits were 0.05 to $1.00 \mathrm{~V}$ vs. RHE. Data collection was performed at the chosen potentials held during anodic sweeps. The electrode was fully cycled following each potential hold in order to clean the electrode surfaces after each potential hold. The data were obtained at the beamline ISS 6-BM in the National Synchrotron Light Source II (NSLS-II) (Brookhaven National Laboratory, NY). Typical experimental procedures were utilized with details provided in our previous work [23]. The data were processed and fitted using the Ifeffit-based Athena [24] and Artemis [25] programs. Scans were calibrated, aligned and normalized with background removed using the IFEFFIT suite [26]. The $\chi(R)$ were modeled using single scattering paths calculated by FEFF6 [27].

\section{RESULTS AND DISCUSSION}

To prepare ultrathin PtCoNWs, PtCo alloy NWs were first prepared by reducing $\mathrm{Pt}(\mathrm{acac})_{2}$ and $\mathrm{Co}(\mathrm{acac})_{2}$ in the mixed solvent of 1-octadecene and oleylamine according to revised synthesis reported previously [13]. The as-prepared PtCoNWs were then loaded onto carbon black (Ketjen black, denoted as $\mathrm{KB}$ ), followed by annealing and acid dealloying processes to produce the final ultrathin PtCoNWs (Fig. 1a). TEM and HAADF-STEM showed that the as-prepared PtCoNWs have a well-defined 1D structure (Fig. 1b and Fig. S1a) with a typical length of 200-300 nm and an average diameter of $1.8 \pm 0.3 \mathrm{~nm}$ (Fig. S1b). The average lattice spacing of $0.191 \mathrm{~nm}$ (Fig. 1d) derived from the fast Fourier transform (FFT) was attributed to the interplane distance of the (200) plane of PtCo alloy. After annealing and dealloying, the resulting PtCoNWs maintained the ultrathin 1D structure (Fig. 1c and Fig. S2a) with an average diameter of $2.3 \pm 0.7 \mathrm{~nm}$ (Fig. S2b). The enlarged diameter may be attributed to ripening during the treatment process. The average lattice spacings of 0.225 and $0.191 \mathrm{~nm}$ along the [011] zone axis were ascribed to (111) and (200) facets, respectively (Fig. 1e). EDX line scan profiles and mapping results revealed that before annealing and dealloying, the as-prepared PtCoNWs had a uniform Pt and Co elemental distribution throughout the

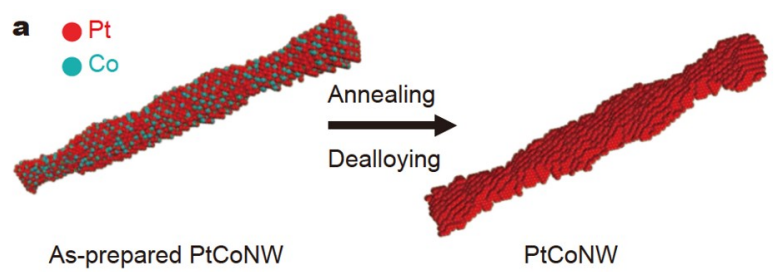

As-prepared PtCoNW
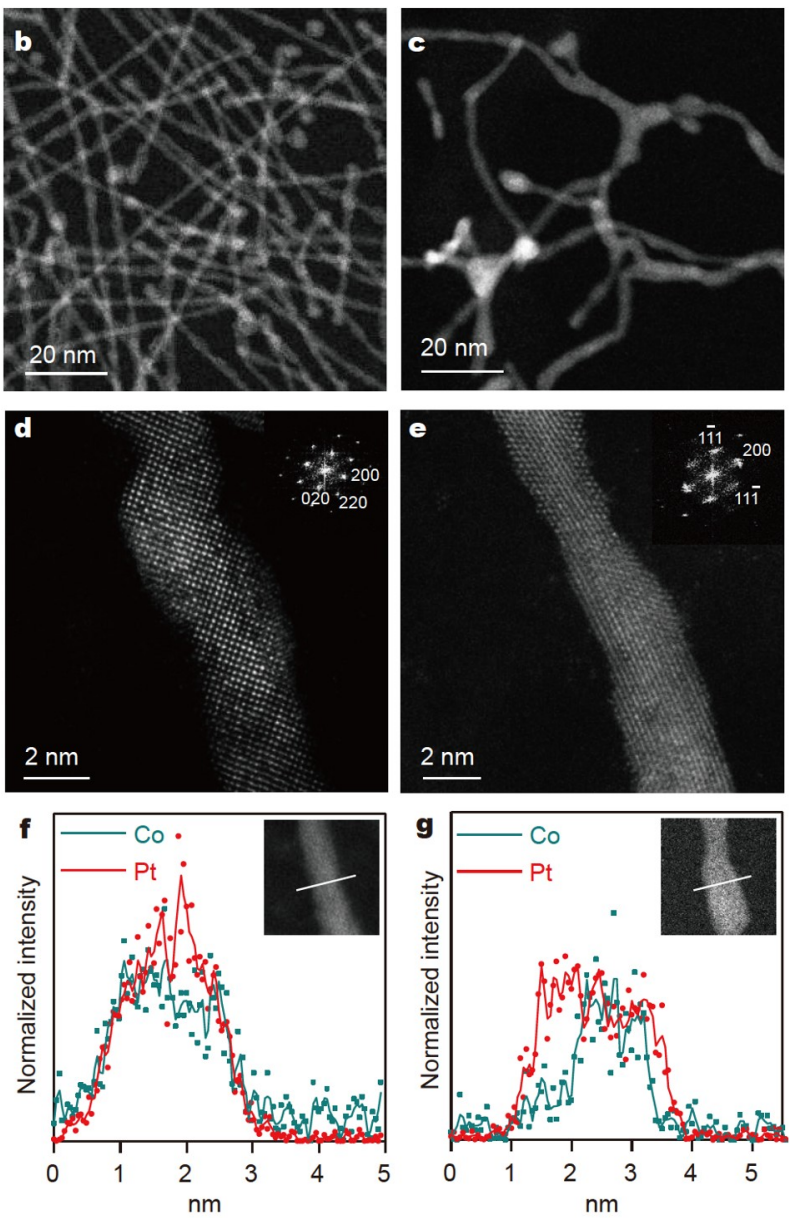

Figure 1 Structural and compositional characterizations of the as-prepared PtCoNWs and ultrathin PtCoNWs after annealing and dealloying. (a) Schematic illustration of transformation from the as-prepared alloy PtCoNWs to ultrathin PtCoNWs with a Pt-rich shell and PtCo-alloy core. (b, c) Representative HAADF-STEM images of the as-prepared PtCoNWs and ultrathin PtCoNWs. (d, e) Atomic resolution STEM images of the asprepared PtCoNWs and ultrathin PtCoNWs; inset is the fast Fouriertransform pattern. ( $f, g$ ) EDX spectroscopy line-scan profiles of the as-prepared PtCoNWs and ultrathin PtCoNWs.

NWs (Fig. 1f and Fig. S1c) with a composition of ca. $\mathrm{Pt}_{67} \mathrm{Co}_{33}$ (Fig. S1d and Table S1). The composition of the final PtCoNWs became ca. $\mathrm{Pt}_{82} \mathrm{Co}_{18}$ upon dealloying, indicating the loss of $\mathrm{Co}$ during the process (Table S1), which is consistent with the ICPAES results. The Pt loading of the PtCoNWs on carbon was determined to be $11.0 \%$ by ICP (Table S2). Moreover, the dealloying process changed the composition distribution from uniformly distributed PtCo alloy NWs to compositional-segregated NWs with PtCo alloy core and Pt-rich skin. As shown in the EDX line scan profiles, the final PtCoNWs have a PtCo core and an ultrathin Pt-rich shell of $0.6 \mathrm{~nm}$ (Fig. 1g). The inverse FFT analysis suggested that the (111) lattice spacings are dif- 

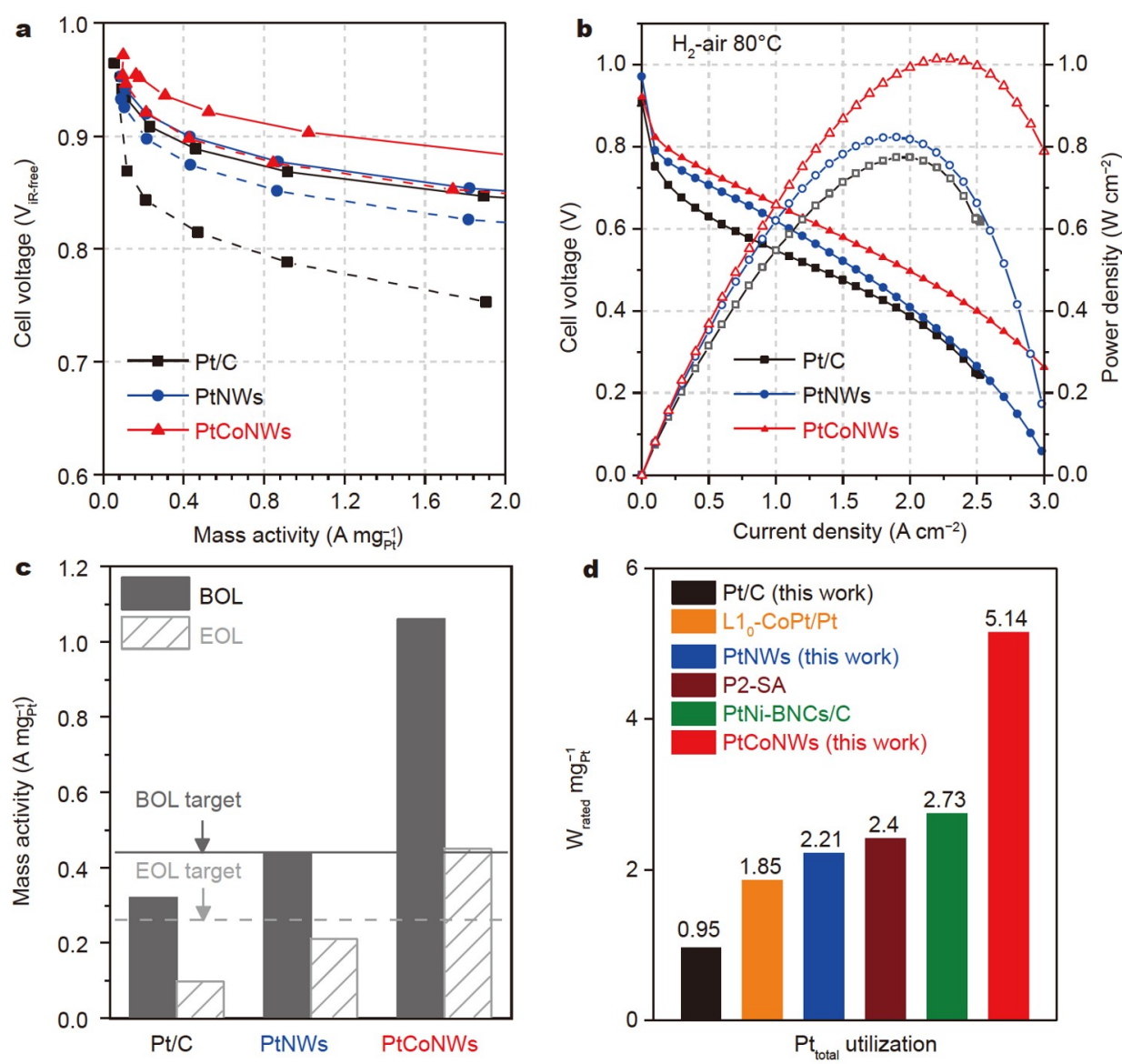

Figure 2 Comparison of MEA performances of PtCoNWs, PtNWs, Pt/C, and state-of-the-art catalysts. (a) The BOL (solid line) and EOL (dashed line) MA polarization curves of Pt/C, PtNWs and PtCoNWs tested in $\mathrm{H}_{2}-\mathrm{O}_{2}$ atmosphere. (b) $\mathrm{H}_{2}$-air current-voltage (I- $V$ ) polarization (solid marks) and power density (hollow marks) curves of Pt/C, PtNWs, and PtCoNWs. (c) Comparison of MAs at $0.9 \mathrm{~V}_{\text {iR-free }}$ for Pt/C, PtNWs, and PtCoNWs. DOE 2020 MA target: $0.44 \mathrm{~A} \mathrm{mg}_{\mathrm{PGM}^{-1}}$ (BOL) and $60 \%$ retention $\left(0.264 \mathrm{~A} \mathrm{mg}_{\mathrm{PGM}}{ }^{-1}\right)$ (EOL). (d) Comparison of total Pt utilization of PtCoNWs with the state-of-the-art values reported previously. The total Pt utilization was calculated by normalizing the rated power density over total Pt loading $\left(\mathrm{Ll}_{0}\right.$-CoPt/Pt: $9 \mathrm{~nm} \mathrm{~L} 1_{0}$-phase intermetallic PtCo NPs [11]; P2-SA: $5 \mathrm{~nm}$ PtNi NPs dealloyed in $0.5 \mathrm{~mol} \mathrm{~L}^{-1}$ sulfuric acid at $80^{\circ} \mathrm{C}$ for $24 \mathrm{~h}$ in nitrogen [33]; PtNi-BNCs/C: Pt-Ni bunched nanocages [10]).

ferent at the core $(0.216 \mathrm{~nm})$ and the shell $(0.227 \mathrm{~nm})$ regions (Fig. S2e, f), indicating higher Pt content in the shell $\left(\mathrm{Pt}_{99} \mathrm{Co}_{1}\right)$ than in the core $\left(\mathrm{Pt}_{52} \mathrm{Co}_{48}\right)$ according to the Vegard's law, consistent with the EDX line scan profiles (Fig. 1g). We also prepared Pt NWs as reference samples following the previously reported approach [13], which were subjected to the same treatment process performed on PtCoNWs. Similarly, PtNWs maintained the morphology after the annealing and acid washing with an average diameter of $1.8 \pm 0.5 \mathrm{~nm}$ (Fig. S3).

We further applied the resulting ultrathin PtCoNWs, PtNWs, and commercial Pt/C (40 wt\% Pt, Alfa Aesar) on the cathode of MEAs and compared their performance in a PEMFC single cell with oxygen or air as the cathodic feeding gas. The MEAs were prepared by ultrasonically spraying the catalysts directly on two sides of the proton-exchange membrane. The geometric $\mathrm{Pt}$ loading in MEAs was fixed at $0.025 \mathrm{mg}_{\mathrm{Pt}} \mathrm{cm}^{-2}$ for the anode and about $0.05 \mathrm{mg}_{\mathrm{Pt}} \mathrm{cm}^{-2}$ for the cathode. The MAs of PtCoNWs, PtNWs, and commercial 40\% Pt/C catalysts in MEA were evaluated in the $\mathrm{H}_{2}-\mathrm{O}_{2}$ atmosphere at $80^{\circ} \mathrm{C}$, using the hydrogencrossover-corrected current densities at $0.9 \mathrm{~V}_{\text {Cell, iR-free. }}$ In both $\mathrm{H}_{2}-\mathrm{O}_{2}$ and $\mathrm{H}_{2}$-Air tests, the PtCoNWs delivered a much higher current density than $\mathrm{PtNW}$ and $\mathrm{Pt} / \mathrm{C}$ in all potential regions (Fig. 2a, b). The PtCoNWs demonstrated an exceptional high
$\mathrm{MA}$ of $1.06 \pm 0.14 \mathrm{~A} \mathrm{mg}_{\mathrm{Pt}^{-1}}$ at $0.9 \mathrm{~V}$ at $\mathrm{BOL}$, which is 2.4 times that of the pure PtNWs $\left(0.44 \mathrm{~A} \mathrm{mg}_{\mathrm{Pt}}{ }^{-1}\right)$ and 3.3 times that of the commercial $40 \% \mathrm{Pt} / \mathrm{C}$ catalysts $\left(0.32 \mathrm{~A} \mathrm{mg}_{\mathrm{Pt}^{-1}}{ }^{-1}\right.$ ) (Fig. 2c), far

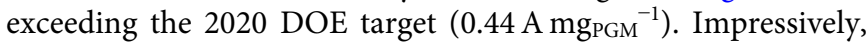
the PtCoNWs exhibited the record-high MA among the state-ofthe-art Pt-alloy catalysts in MEAs (Table 1).

The structural details of PtCoNWs were studied using in-situ XAS. The white line intensity of the X-ray absorption near-edge structure (XANES) spectrum of PtCoNWs (Fig. S4a) at the Pt $\mathrm{L}_{3}$-edge decreased (red arrow) compared with that of $\mathrm{Pt} / \mathrm{C}$ reference, indicating decreasing Pt d-band vacancies due to the formation of the PtCo alloy [28]. The extended X-ray absorption fine structure (EXAFS) fitting result showed the first-shell $\mathrm{Pt}-\mathrm{Pt}$ bond length of PtCoNWs is $2.72 \AA$ (Fig. S4c and Table S3), which is about $1.1 \%$ shorter than that in $\mathrm{Pt} / \mathrm{C}(2.75 \AA)$. Furthermore, the degree of alloying of the bimetallic PtCoNWs structures was indicated by analyzing the extent of alloying $(J$ factor) that was derived from the first-shell coordination numbers (CNs) [29]. In PtCoNWs, the $J_{\mathrm{Pt}}$ and $J_{\mathrm{Co}}$ values were determined to be 1.3 and 1.0 , respectively (Table $S 3$ ), which are higher than those expected for disordered alloyed structure $(J=$ 1), indicating a well-mixed distribution of Pt and Co atoms [30]. These results showed that PtCoNWs possessed a high degree of 
Table 1 Comparisons of the MEA performance among the state-of-the-art catalysts

\begin{tabular}{|c|c|c|c|c|c|c|c|}
\hline \multirow{2}{*}{ Catalyst } & \multirow{2}{*}{$\begin{array}{l}\text { Total loading (anode }+ \\
\text { cathode) }\left(\mathrm{mg}_{\mathrm{PGM}} \mathrm{cm}^{-2}\right)\end{array}$} & \multicolumn{2}{|c|}{ MA (A mg $\left.{ }^{-1}\right)$} & \multirow{2}{*}{$\begin{array}{c}\text { AST } \\
\text { condition }\end{array}$} & \multirow{2}{*}{$\begin{array}{l}\text { Power density at } \\
0.6 \mathrm{~V}\left(\mathrm{~mW} \mathrm{~cm}^{-2}\right)\end{array}$} & \multirow{2}{*}{$\begin{array}{l}\text { Peak power } \\
\text { density } \\
\left(\mathrm{mW} \mathrm{cm}^{-2}\right)\end{array}$} & \multirow{2}{*}{$\begin{array}{l}\mathrm{H}_{2} \text {-air test } \\
\text { condition }\end{array}$} \\
\hline & & BOL & EOL & & & & \\
\hline PtCoNWs (This work) & $\begin{array}{c}0.072 \\
(0.025+0.047)\end{array}$ & 1.06 & 0.45 & \multirow{3}{*}{$\begin{array}{l}\text { Square wave: } \\
0.6-0.95 \mathrm{~V} \text {, } \\
30,000 \text { cycles }\end{array}$} & 840 & 1016 & \multirow{3}{*}{$\begin{array}{c}\text { Nafion } \mathrm{HP}, 80^{\circ} \mathrm{C} \text {, } \\
150 \mathrm{kPa}, 100 \% \\
\mathrm{RH}\end{array}$} \\
\hline PtNWs (This work) & $\begin{array}{c}0.077 \\
(0.025+0.052)\end{array}$ & 0.44 & 0.21 & & 660 & 830 & \\
\hline Pt/C (This work) & $\begin{array}{c}0.075 \\
(0.025+0.050)\end{array}$ & 0.32 & 0.098 & & 402 & 773 & \\
\hline PtNi-BNSs/C ${ }^{c}[10]$ & $0.25(0.1+0.15)$ & $\mathrm{NA}^{\mathrm{b}}$ & NA & \multirow{2}{*}{$\begin{array}{l}\text { Air-conditioned at } \\
\text { room temperature of } \\
<26^{\circ} \mathrm{C} \text { for } 180 \mathrm{~h}\end{array}$} & 600 & 770 & \multirow{3}{*}{$\begin{array}{c}\text { Nafion } 212,80^{\circ} \mathrm{C} \text {, } \\
300 \mathrm{kPa}, 100 \% \\
\mathrm{RH} \\
\text { Nafion } 211,80^{\circ} \mathrm{C} \text {, } \\
150 \mathrm{kPa}, 100 \% \\
\mathrm{RH}\end{array}$} \\
\hline PtNi-BNCs/C ${ }^{d}[10]$ & $0.25(0.1+0.15)$ & NA & NA & & 900 & 920 & \\
\hline $\mathrm{L} 1_{0}-\mathrm{CoPt} / \mathrm{Pt}^{\mathrm{e}}[11]$ & $0.205(0.1+0.105)$ & 0.56 & 0.45 & $\begin{array}{c}\text { Trapezoidal wave: } 0.6- \\
0.95 \mathrm{~V}, 30,000 \text { cycles }\end{array}$ & 570 & NA & \\
\hline PtNi NW array $^{f}[39]$ & $0.312^{* a}$ & 0.07 & 0.051 & \multirow{2}{*}{$\begin{array}{c}0.6-1.2 \mathrm{~V} \\
\left(100 \mathrm{mV} \mathrm{s}^{-1}\right) \\
3000 \text { cycles }^{-}\end{array}$} & 541 & NA & \multirow{2}{*}{$\begin{array}{c}\text { Nafion } 212,80^{\circ} \mathrm{C} \text {, } \\
\text { cathode/anode: } \\
230 / 250 \mathrm{kPa}, \\
30 \% / 50 \% \mathrm{RH}\end{array}$} \\
\hline Pt NW array ${ }^{g}$ [39] & $0.312^{*}$ & 0.062 & 0.064 & & 504 & NA & \\
\hline $\mathrm{P} 2-\mathrm{SA}^{\mathrm{h}}[33]$ & $0.15(0.05+0.1)$ & 0.64 & 0.5 & \multirow{2}{*}{$\begin{array}{c}\text { Triangle wave: } 0.6- \\
1.0 \mathrm{~V}\left(50 \mathrm{mV} \mathrm{s}^{-1}\right) \\
30,000 \text { cycles }\end{array}$} & 900 & NA & \multirow{2}{*}{$\begin{array}{c}\text { Nafion } 211,80^{\circ} \mathrm{C}, \\
170 \mathrm{kPa}, 100 \% \\
\mathrm{RH}\end{array}$} \\
\hline $\mathrm{P} 2-\mathrm{NA}^{\mathrm{i}}[33]$ & $0.15(0.05+0.1)$ & 0.62 & 0.43 & & 900 & NA & \\
\hline
\end{tabular}

a) *: assuming this is the total loading of Pt due to missing specification; b) NA: not available; c) PtNi-BNSs/C: Pt-Ni bunched nanospheres [10]; d) PtNiBNCs/C: Pt-Ni bunched nanocages [10]; e) $\mathrm{L1}_{0}$-CoPt/Pt: $9 \mathrm{~nm} \mathrm{L1} 1_{0}$-phase intermetallic PtCo NPs [11]; f) PtNi NW array: PtNi NW array gas diffusion electrode [39]; g) Pt NW array: Pt NW array gas diffusion electrode [39]; h) P2-SA: $5 \mathrm{~nm} \mathrm{PtNi} \mathrm{NPs} \mathrm{dealloyed} \mathrm{in} 0.5 \mathrm{~mol} \mathrm{~L}^{-1}$ sulfuric acid at 80 ${ }^{\circ} \mathrm{C}$ for 24 h in nitrogen [33]; i) P2-NA: $5 \mathrm{~nm}$ PtNi NPs dealloyed in $1 \mathrm{~mol} \mathrm{~L}^{-1}$ nitric acid at $70^{\circ} \mathrm{C}$ for $24 \mathrm{~h}$ in nitrogen [33].

alloying, which may promote ligand effect and mitigate Pt dissolution [31,32]. The intrinsic activity measured on RDE confirmed the beneficial strain effect and ligand effect (Fig. S5a, b). We also performed the stability test on RDE between 0.6 to $1.0 \mathrm{~V}$ versus RHE at a scan rate of $100 \mathrm{mV} \mathrm{s}^{-1}$ for PtCoNWs and PtNWs (Fig. S5c, d). The PtCoNWs showed an MA retention of $106 \%$ after 10,000 cycles of stability test, which is better than that of the PtNWs (86\%) and Pt/C (69\%). Importantly, both PtCoNWs and PtNWs maintained 1D morphology after 10,000 cycles in RDE, which may help activity retention in MEA (Fig. S5e, f).

Importantly, when incorporated in MEA (ca. $0.05 \mathrm{mg}_{\mathrm{Pt}} \mathrm{cm}^{-2}$ at cathode), the PtCoNWs delivered a large ECSA of $73.2 \mathrm{~m}^{2} \mathrm{gPt}^{-1}$, which was much higher than that of PtNWs $\left(47.0 \mathrm{~m}^{2} \mathrm{~g}_{\mathrm{Pt}}{ }^{-1}\right)$ and $\mathrm{Pt} / \mathrm{C}\left(33.0 \mathrm{~m}^{2} \mathrm{~g}_{\mathrm{Pt}}{ }^{-1}\right)$ (Fig. S6). The PtNWs only demonstrated a modest ECSA despite a smaller average diameter, suggesting that PtNWs might suffer more coalescence or dissolution during the activation process. Indeed, after the MA measurement, PtCoNWs maintained the 1D morphology with a size distribution of $3.1 \pm 0.9 \mathrm{~nm}$ (Fig. S7a). Under the same conditions, however, PtNWs evolved into nanorods and NPs with a size distribution of $3.6 \pm 1.1 \mathrm{~nm}$ and $3.9 \pm 0.6 \mathrm{~nm}$, respectively (Fig. S8). Therefore, the large ECSA of PtCoNWs may be attributed to their 1D structure with a high surface area that was well maintained after the MA measurement as evidenced in Fig. $3 \mathrm{a}$ and Fig. S7. In addition, the inverse FFT analysis of the PtCoNWs after MEA test further confirmed that the segregated structure of Pt-rich shell $\left(\mathrm{Pt}_{98} \mathrm{Co}_{2}\right)$ and the alloy core $\left(\mathrm{Pt}_{59} \mathrm{Co}_{41}\right)$ was also retained, showing different (111) lattice spacings at the core $(0.218 \mathrm{~nm})$ and the shell $(0.227 \mathrm{~nm})$ regions (Fig. S7e, f). Impressively, the composition changed only slightly from $\mathrm{Pt}_{82} \mathrm{Co}_{18}$ to $\mathrm{Pt}_{86} \mathrm{Co}_{14}$ after the MA measurement (Fig. S7g and Table S1). All suggest excellent intrinsic structural and compo- sitional stability of the PtCoNWs in MEA.

The outstanding MA and large ECSA enabled the PtCoNWs to exhibit high power density in $\mathrm{H}_{2}$-air tests (Fig. 2b). The PtCoNWs and PtNWs showed higher current density than that of $\mathrm{Pt} / \mathrm{C}$ at all potential regions. The PtCoNWs delivered a current density of $1.4 \mathrm{~A} \mathrm{~cm}^{-2}$ at $0.6 \mathrm{~V}$ cell voltage [10] and reached a peak power density of $1016 \mathrm{~mW} \mathrm{~cm}^{-2}$, outperforming the PtNWs $\left(1.1 \mathrm{~A} \mathrm{~cm}^{-2}\right.$ at $0.6 \mathrm{~V}$ and $\left.830 \mathrm{~mW} \mathrm{~cm}^{-2}\right)$ and $\mathrm{Pt} / \mathrm{C}\left(0.67 \mathrm{~A} \mathrm{~cm}^{-2}\right.$ at $0.6 \mathrm{~V}$ and $773 \mathrm{~mW} \mathrm{~cm}^{-2}$ ). At an even higher current density of $2.5 \mathrm{~A} \mathrm{~cm}^{-2}$, PtCoNWs still delivered a power density of $1000 \mathrm{~mW} \mathrm{~cm}^{-2}$, while PtNWs only showed a power density of $666 \mathrm{~mW} \mathrm{~cm}^{-2}$, comparable to that of $\mathrm{Pt} / \mathrm{C}\left(626 \mathrm{~mW} \mathrm{~cm}^{-2}\right)$. The above power density performance analysis suggested that $1 \mathrm{D}$ PtCoNWs showed a lower $\mathrm{O}_{2}$ transport resistance than the NP $\mathrm{Pt} / \mathrm{C}$ at the low loading scenario. We also evaluated the rated power, at which the heat rejection balance $(Q / \Delta T i<1.45)$ should be considered for practical operation yet rarely reported and overlooked. The rated power was determined at $0.76 \mathrm{~V}$ for cells operated at $80^{\circ} \mathrm{C}$. The PtCoNWs delivered a rated power of $0.37 \mathrm{~W} \mathrm{~cm}^{-2}$, which is 5.2 times that of $\mathrm{Pt} / \mathrm{C}\left(0.071 \mathrm{~W} \mathrm{~cm}^{-2}\right)$ and 2.2 times that of the PtNWs $\left(0.17 \mathrm{~W} \mathrm{~cm}^{-2}\right)$. This corresponds to an ultrahigh total effective Pt utilization of $5.14 \mathrm{~W}_{\text {rated }} \mathrm{mg}_{\mathrm{Pt}}{ }^{-1}$ for PtCoNWs, which is 5.4 times that of $\mathrm{Pt} / \mathrm{C}\left(0.95 \mathrm{~W}_{\text {rated }} \mathrm{mg}_{\mathrm{Pt}}{ }^{-1}\right)$, surpassing all the state-of-the-art Pt-alloy catalysts in MEA (Fig. 2d). The high Pt utilization demonstrated the efficiency of 1D PtCoNW structures in MEA, which can significantly reduce the usage of $\mathrm{Pt}$ while delivering high performance in PEMFCs.

Furthermore, despite the high activity of several Pt-alloy catalysts reported to date, the report of their durability in MEA has been rare [34,35]. We followed the DOE-suggested protocol [7] to evaluate the durability of the catalysts by applying the squarewave potential cycling between 0.60 and $0.95 \mathrm{~V}$ for 30,000 cycles. The PtCoNWs showed an impressive EOL MA of $0.45 \mathrm{~A} \mathrm{mg}_{\mathrm{Pt}^{-1}}$, 

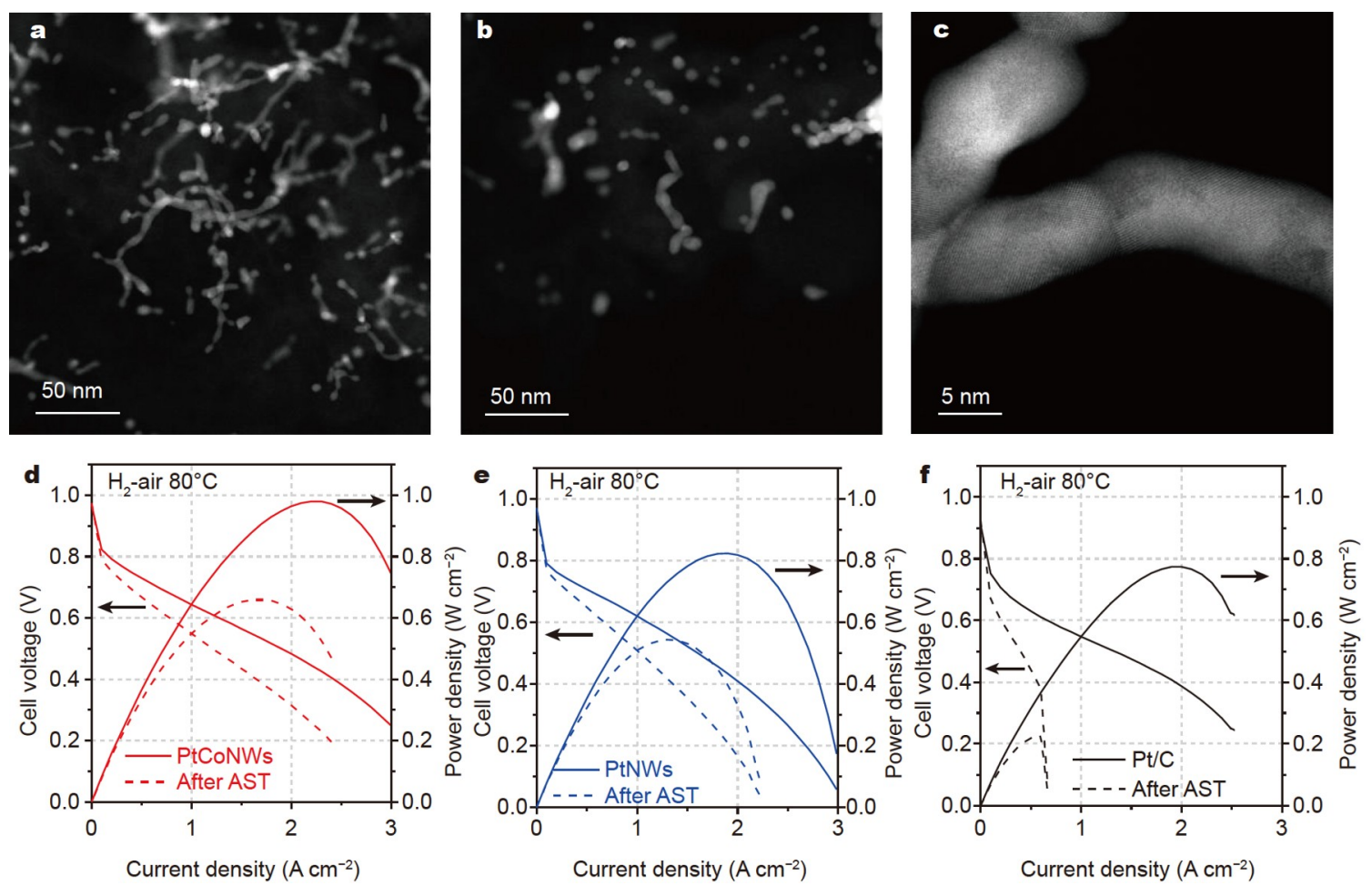

Figure 3 Durability analysis of catalysts. HAADF-TEM images of PtCoNWs (a) at BOL and (b) at EOL stage. (c) High-resolution STEM image of PtCoNWs after AST. Comparison of $\mathrm{H}_{2}$-air performance of (d) PtCoNWs, (e) PtNWs, and (f) Pt/C catalysts at the BOL (solid line) and EOL (dashed line) stage.

which is still above the BOL MA target of DOE $\left(0.44 \mathrm{~A} \mathrm{mg}_{\mathrm{PGM}^{-1}}{ }^{-1}\right)$ (Fig. 2c). On the other hand, the MA of PtNWs and Pt/C after AST decayed to 0.21 and $0.1 \mathrm{~A} \mathrm{mg}_{\mathrm{Pt}}{ }^{-1}$, respectively, both below the DOE EOL target of $0.26 \mathrm{~A} \mathrm{mg}_{\mathrm{PGM}}{ }^{-1}$ (Fig. 2c).

To investigate the degradation behavior, we also performed the characterizations on the catalysts after AST in MEA. Severe aggregation and shape deformation were observed in all catalyst groups. We observed that considerable PtCoNWs maintained the 1D structure, while some tended to evolve into NPs (Fig. 3b, c), which might contribute to the performance loss. After AST, the Pt-skin on PtCoNWs still remained as suggested by the inverse FFT and EDX line scan results (Fig. S9c, g). The mean diameter of PtCoNWs increased from $3.1 \pm 0.9$ to $6.6 \pm 1.9 \mathrm{~nm}$ (Fig. 3a, b), leading to a decreased ECSA of $36.2 \mathrm{~m}^{2} \mathrm{~g}_{\mathrm{pt}}{ }^{-1}$ (Fig. S6), which, however, was still larger than the initial ECSA of $\mathrm{Pt} / \mathrm{C}\left(33.0 \mathrm{~m}^{2} \mathrm{~g}_{\mathrm{Pt}}^{-1}\right)$. For the PtNWs, a more pronounced morphology change was observed after AST, where nearly all PtNWs evolved into spherical NPs $(4.6 \pm 1.2 \mathrm{~nm})$ and showed a low ECSA of $15.4 \mathrm{~m}^{2} \mathrm{~g}_{\mathrm{Pt}}{ }^{-1}$ (Figs S6 and S10a, c). Likewise, the Pt/ $\mathrm{C}$ suffered significant aggregation after AST with average size increasing from $5.3 \pm 1.2$ to $8.8 \pm 6.4 \mathrm{~nm}$, and the ECSA dropped from 33.0 to $11.7 \mathrm{~m}^{2} \mathrm{~g}_{\mathrm{Pt}}{ }^{-1}$ (Figs S6 and S10b, d). In addition to aggregation, the loss of activity could also be partly attributed to the nonoptimal attachment between the catalysts and the carbon support. After AST, the density of nanocatalysts on carbon support apparently decreased (Fig. S10c), indicating the detachment and loss of catalyst. This problem is commonly reported in the degradation mechanism of fuel cell catalysts [3638].

Overall, both PtCoNWs and PtNWs demonstrated better structural stability than Pt/C. And the PtCoNWs demonstrated much better structural stability compared to $\mathrm{Pt} / \mathrm{C}$, which may be attributed to their uniform alloying Pt-Co core. In addition, EDX analysis revealed that PtCoNWs retained most of the Co after AST, where the composition of Co only slightly changed from ca. $14 \%$ to $9 \%$ (Fig. S9h and Table S1), indicating composition stability. After AST, the PtCoNWs still delivered a peak power density of $662 \mathrm{~mW} \mathrm{~cm}^{-2}$ (Fig. 3d), while the peak power of $\mathrm{PtNW}$ and $\mathrm{Pt} / \mathrm{C}$ decayed to 546 and $220 \mathrm{~mW} \mathrm{~cm}^{-2}$, respectively (Fig. 3e, f). 1D NW structures demonstrated much better performance in both MA and power performance compared with $\mathrm{NPs}(\mathrm{Pt} / \mathrm{C})$, while PtCo alloy demonstrated superiority over pure $\mathrm{Pt}$, confirming the advantages and better structural durability of 1D Pt-alloy catalysts in PEMFC applications. Through the comparison of the structures and compositions of all catalyst groups, it becomes more evident that 1D morphology showed better structural stability than the NP Pt/C, and that PtCo alloy core further contributed to the higher stability of PtCoNWs, which resulted in the decent activity and power density after AST and can potentially overcome the dilemma between low loading and high-power density.

\section{CONCLUSION}

In summary, we demonstrated an ultralow Pt loading and highperformance MEA using ultrathin PtCoNWs. The PtCoNWs showed a high BOL ECSA of $73.2 \mathrm{~m}^{2} \mathrm{gPt}_{\mathrm{Pt}}^{-1}$, a record-high MA of $1.06 \mathrm{~A} \mathrm{mg}_{\mathrm{Pt}^{-1}}{ }^{-1}$, and excellent structural and composition stability in a MEA, outperforming most state-of-the-art Pt-alloy catalysts in MEA reported to date (Table 1) and surpassing DOE set 2020 targets. PtCoNWs also delivered an impressively high Pt utilization of $5.14 \mathrm{~W}_{\text {rated }} \mathrm{mg}_{\mathrm{pt}}{ }^{-1}$ at $80^{\circ} \mathrm{C}$, with ultralow cathode $\mathrm{Pt}$ loading of $0.047 \mathrm{mg}_{\mathrm{Pt}} \mathrm{cm}^{-2}$, suggesting a valid pathway to over- 
come the dilemma between low loading and high-power density using ultrathin $1 \mathrm{D}$ catalysts.

\section{Received 5 August 2021; accepted 17 August 2021; published online 29 September 2021}

1 Debe MK. Electrocatalyst approaches and challenges for automotive fuel cells. Nature, 2012, 486: 43-51

2 Wang XX, Swihart MT, Wu G. Achievements, challenges and perspectives on cathode catalysts in proton exchange membrane fuel cells for transportation. Nat Catal, 2019, 2: 578-589

3 Kodama K, Nagai T, Kuwaki A, et al. Challenges in applying highly active Pt-based nanostructured catalysts for oxygen reduction reactions to fuel cell vehicles. Nat Nanotechnol, 2021, 16: 140-147

$4 \mathrm{Wu}$ J, Yang H. Platinum-based oxygen reduction electrocatalysts. Acc Chem Res, 2013, 46: 1848-1857

5 Whiston MM, Azevedo IL, Litster S, et al. Expert assessments of the cost and expected future performance of proton exchange membrane fuel cells for vehicles. Proc Natl Acad Sci U S A, 2019, 116: 4899-4904

6 Kongkanand A, Mathias MF. The priority and challenge of high-power performance of low-platinum proton-exchange membrane fuel cells. J Phys Chem Lett, 2016, 7: 1127-1137

7 DRIVE US. Fuel cell technical team roadmap. Secondary fuel cell technical team roadmap, 2017, November: https://www.energy.gov/ sites/prod/files/2017/11/f46/FCTT_Roadmap_Nov_2017_FINAL.pdf

8 Kriston Á, Xie T, Gamliel D, et al. Effect of ultra-low Pt loading on mass activity of polymer electrolyte membrane fuel cells. J Power Sources, 2013, 243: 958-963

9 Fan J, Chen M, Zhao Z, et al. Bridging the gap between highly active oxygen reduction reaction catalysts and effective catalyst layers for proton exchange membrane fuel cells. Nat Energy, 2021, 6: 475-486

10 Tian X, Zhao X, Su YQ, et al. Engineering bunched Pt-Ni alloy nanocages for efficient oxygen reduction in practical fuel cells. Science, 2019, 366: 850-856

11 Li J, Sharma S, Liu X, et al. Hard-magnet $\mathrm{L1}_{0}-\mathrm{CoPt}$ nanoparticles advance fuel cell catalysis. Joule, 2019, 3: 124-135

12 Liu Z, Zhao Z, Peng B, et al. Beyond extended surfaces: Understanding the oxygen reduction reaction on nanocatalysts. J Am Chem Soc, 2020, 142: $17812-17827$

13 Li M, Zhao Z, Cheng T, et al. Ultrafine jagged platinum nanowires enable ultrahigh mass activity for the oxygen reduction reaction. Science, 2016, 354: 1414-1419

14 Sandbeck DJS, Secher NM, Inaba M, et al. The dissolution dilemma for low Pt loading polymer electrolyte membrane fuel cell catalysts. J Electrochem Soc, 2020, 167: 164501

$15 \mathrm{Lu} \mathrm{Y}, \mathrm{Du}$ S, Steinberger-Wilckens R. One-dimensional nanostructured electrocatalysts for polymer electrolyte membrane fuel cells-A review. Appl Catal B-Environ, 2016, 199: 292-314

16 Chen Y, Cheng T, Goddard III WA. Atomistic explanation of the dramatically improved oxygen reduction reaction of jagged platinum nanowires, 50 times better than Pt. J Am Chem Soc, 2020, 142: 86258632

17 Fuchs T, Drnec J, Calle-Vallejo F, et al. Structure dependency of the atomic-scale mechanisms of platinum electro-oxidation and dissolution. Nat Catal, 2020, 3: 754-761

$18 \mathrm{Bu} \mathrm{L}$, Guo S, Zhang X, et al. Surface engineering of hierarchical platinum-cobalt nanowires for efficient electrocatalysis. Nat Commun, 2016, 7: 11850

19 Jiang K, Zhao D, Guo S, et al. Efficient oxygen reduction catalysis by subnanometer Pt alloy nanowires. Sci Adv, 2017, 3: e1601705

20 Stephens IEL, Rossmeisl J, Chorkendorff I. Toward sustainable fuel cells. Science, 2016, 354: 1378-1379

21 Sievers GW, Jensen AW, Quinson J, et al. Self-supported Pt-CoO networks combining high specific activity with high surface area for oxygen reduction. Nat Mater, 2021, 20: 208-213

22 Arruda TM, Shyam B, Ziegelbauer JM, et al. Investigation into the competitive and site-specific nature of anion adsorption on Pt using in situ X-ray absorption spectroscopy. J Phys Chem C, 2008, 112: 18087-
18097

23 Jia Q, Liang W, Bates MK, et al. Activity descriptor identification for oxygen reduction on platinum-based bimetallic nanoparticles: In situ observation of the linear composition-strain-activity relationship. ACS Nano, 2015, 9: 387-400

24 Newville M. IFEFFIT: Interactive XAFS analysis and FEFF fitting. J Synchrotron Rad, 2001, 8: 322-324

25 Ravel B, Newville M. ATHENA, ARTEMIS, HEPHAESTUS: Data analysis for X-ray absorption spectroscopy using IFEFFIT. J Synchrotron Rad, 2005, 12: 537-541

26 Newville M, Livins P, Yacoby $\mathrm{Y}$, et al. Near-edge X-ray-absorption fine structure of $\mathrm{Pb}$ : A comparison of theory and experiment. Phys Rev B, 1993, 47: 14126-14131

27 Ankudinov AL, Ravel B, Rehr JJ, et al. Real-space multiple-scattering calculation and interpretation of X-ray-absorption near-edge structure. Phys Rev B, 1998, 58: 7565-7576

28 Hlil EK, Baudoing-Savois R, Moraweck B, et al. X-ray absorption edges in platinum-based alloys. 2. Influence of ordering and of the nature of the second metal. J Phys Chem, 1996, 100: 3102-3107

29 Jia Q, Caldwell K, Ramaker DE, et al. In situ spectroscopic evidence for ordered core-ultrathin shell $\mathrm{Pt}_{1} \mathrm{Co}_{1}$ nanoparticles with enhanced activity and stability as oxygen reduction electrocatalysts. J Phys Chem C, 2014, 118: 20496-20503

30 Hwang BJ, Sarma LS, Chen JM, et al. Structural models and atomic distribution of bimetallic nanoparticles as investigated by X-ray absorption spectroscopy. J Am Chem Soc, 2005, 127: 11140-11145

31 Kim HY, Kim JM, Ha Y, et al. Activity origin and multifunctionality of Pt-based intermetallic nanostructures for efficient electrocatalysis. ACS Catal, 2019, 9: 11242-11254

32 Wang Z, Yao X, Kang Y, et al. Structurally ordered low-Pt intermetallic electrocatalysts toward durably high oxygen reduction reaction activity. Adv Funct Mater, 2019, 29: 1902987

33 Han B, Carlton CE, Kongkanand A, et al. Record activity and stability of dealloyed bimetallic catalysts for proton exchange membrane fuel cells. Energy Environ Sci, 2015, 8: 258-266

34 Chong L, Wen J, Kubal J, et al. Ultralow-loading platinum-cobalt fuel cell catalysts derived from imidazolate frameworks. Science, 2018, 362: $1276-1281$

35 Zhao Z, Hossain MD, Xu C, et al. Tailoring a three-phase microenvironment for high-performance oxygen reduction reaction in proton exchange membrane fuel cells. Matter, 2020, 3: 1774-1790

36 Shao Y, Yin G, Gao Y. Understanding and approaches for the durability issues of Pt-based catalysts for PEM fuel cell. J Power Sources, 2007, 171: $558-566$

37 Beermann V, Holtz ME, Padgett E, et al. Real-time imaging of activation and degradation of carbon supported octahedral Pt-Ni alloy fuel cell catalysts at the nanoscale using in situ electrochemical liquid cell STEM. Energy Environ Sci, 2019, 12: 2476-2485

38 Takao S, Sekizawa O, Samjeské G, et al. Observation of degradation of $\mathrm{Pt}$ and carbon support in polymer electrolyte fuel cell using combined nano-X-ray absorption fine structure and transmission electron microscopy techniques. ACS Appl Mater Interfaces, 2018, 10: 2773427744

39 Mardle P, Thirunavukkarasu G, Guan S, et al. Comparative study of $\mathrm{PtNi}$ nanowire array electrodes toward oxygen reduction reaction by half-cell measurement and PEMFC test. ACS Appl Mater Interfaces, 2020, 12: 42832-42841

Acknowledgements Huang Y, Jia Q, and Duan X acknowledge the support from the Office of Naval Research (N000141812155). Huang Y acknowledges the support from the National Science Foundation (DMREF 1437263). This research used beamline 6-BM of the National Synchrotron Light Source II, a U.S. Department of Energy (DOE) Office of Science User Facility operated for the DOE Office of Science by Brookhaven National Laboratory under Contract No. DE-SC0012704. The authors acknowledge the use of facilities and instrumentation at the UC Irvine Materials Research Institute (IMRI), which is supported in part by the National Science Foundation through the UC Irvine Materials Research Science and Engineering Center (DMR- 
2011967). The authors also acknowledge the Electron Imaging Center of Nanomachines at CNSI, UC Los Angeles for TEM support.

Author contributions Huang Y supervised the project. Huang J and Peng $\mathrm{B}$ designed and performed the experiments. Stracensky $\mathrm{T}$ and Jia Q performed the XAS characterization. Xu M helped with the STEM characterization. Liu $\mathrm{Z}$ and Zhao $\mathrm{Z}$ helped with the MEA measurement. Liu $\mathrm{Y}$ and Zhang A helped with the synthesis of catalysts. Huang J, Peng B, and Huang $\mathrm{Y}$ wrote and revised the manuscript. All authors reviewed and commented on the manuscript.

Conflict of interest The authors declare that they have no conflict of interest.

Supplementary information Supporting data are available in the online version of the paper.

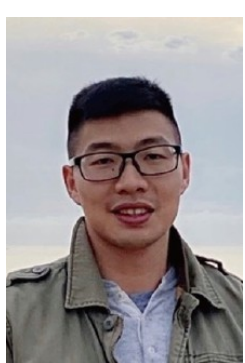

Jin Huang received his B.Eng. degree from the School of Materials Science and Engineering, Wuhan University of Technology (WUT) in 2016. He is currently a $\mathrm{PhD}$ candidate at the Department of Materials Science and Engineering, the University of California, Los Angeles (UCLA) under Prof. Yu Huang's supervision. His research is focused on the catalysis for energy conversion.

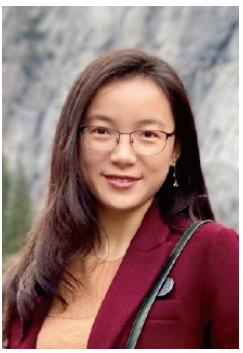

Bosi Peng received her BS degree from the College of Chemistry and Molecular Sciences, Wuhan University in 2017. She is currently a $\mathrm{PhD}$ candidate at the Department of Chemistry and Biochemistry, the UCLA under the supervision of Prof. Yu Huang and Prof. Xiangfeng Duan. Her research interests include electrocatalysis for clean energy conversion.

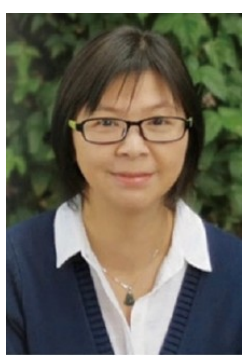

Yu Huang is currently a full professor and chair of the Department of Materials Science and Engineering at the UCLA. Her research centers around mechanistic understanding of nanoscale phenomena and exploiting the unique properties of nanoscale materials for various applications including materials synthesis, catalysis, fuel cells, biomedical and device applications.

\section{一维PtCo纳米线作为低Pt负载PEMFC的催化剂}

黄进 ${ }^{1 \dagger}$, 彭博思 ${ }^{1,2 \dagger}$, Thomas Stracensky ${ }^{3}$, 刘泽延 ${ }^{1}$, 张朝 ${ }^{1}$, 徐明杰 ${ }^{4,5}$, 刘洋 ${ }^{1}$, 赵紫鹏 ${ }^{1}$, 段镶锋 ${ }^{2,6}$, 贾晴鹰 ${ }^{3}$, 黄昱 ${ }^{1,6^{*}}$

摘要 质子交换膜燃料电池 (PEMFC)中使用的高成本铂族金属 (PGM) 催化剂阻碍了其广泛应用. 尽管使用低铂负载量的燃料电池可以很大 程度克服这一挑战, 但是电池的高电流密度性能将因此严重降低. 为了 克服这一两难困境, 我们报道了超细铂钴纳米线( $\mathrm{PtCoNWs}$ ) 作为超低 铂负载和高性能膜电极组件 (MEA) 阴极催化剂的开发. PtCoNWs在 MEA中的氧还原反应 $(\mathrm{ORR})$ 展现出 $1.06 \pm 0.14 \mathrm{~A} \mathrm{mg}_{\mathrm{Pt}}{ }^{-1}$ 的破纪录的高 质量活性 (MA), 因此获得了 $5.14 \mathrm{~W}_{\mathrm{rate}} \mathrm{mg}_{\mathrm{Pt}}{ }^{-1}$ 的极佳的铂利用率. 在 30,000 次方波加速稳定性测试(AST)后, PtCoNW保持了 $0.45 \mathrm{~A} \mathrm{mgt}_{\mathrm{Pt}}{ }^{-1}$ 的可观的终止寿命(EOL)质量活性，仍高于美国能源部2020年催化剂寿 命开始(BOL)目标. 原位X射线吸收光谱(XAS)研究表明, PtCoNWs中的 高度合金化稳定了超细结构, 并可能有助于PEMFC中的高ORR活性和 功率密度性能 